Received: 14 February 2018

Accepted: 18 July 2018

Published online: 16 August 2018
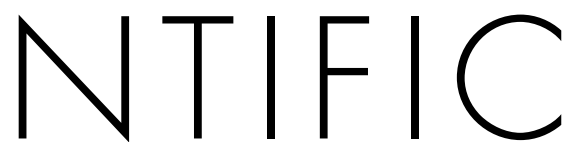

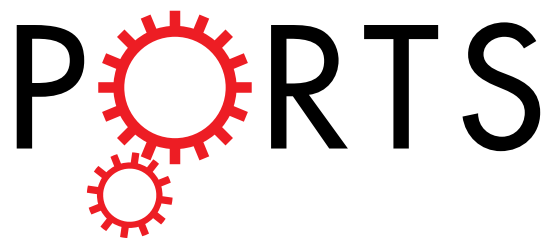

\title{
OPEN Hematopoietic reconstitution of neonatal immunocompetent mice to study conditions with a perinatal window of susceptibility
}

Karen Laky, Philip Dugan \& Pamela A. Frischmeyer-Guerrerio

Efficient hematopoietic reconstitution of wild type mice requires preconditioning. Established experimental protocols exist to transplant hematopoietic stem cells into lethally irradiated or chemically myeloablated adult mice or unirradiated immunodeficient mice. We sought to develop a protocol to reconstitute immuno-replete neonatal mice. We describe irradiation and injection procedures for two-day old mice that lead to efficient long-term reconstitution of primary and secondary lymphoid organs. We demonstrate that the frequencies of lymphoid and myeloid cells in primary and secondary lymphoid organs are indistinguishable from unirradiated uninjected sex- and age-matched control animals by 5 weeks post-reconstitution. Thus, this system will facilitate studies aimed at understanding the developmental and environmental mechanisms that contribute to conditions that have a window of susceptibility during the perinatal period.

In recent years, the importance of early life events on the subsequent development of human disease that may not manifest until late childhood or even adulthood has become increasingly appreciated ${ }^{1}$. The perinatal period is a critical developmental window where environmental exposures, epigenetic changes, microbial exposures, and infectious contacts can influence the development and function of multiple organ systems and thus susceptibility to diseases including obesity, chronic kidney disease, neuro-psychiatric conditions, cardiovascular disease, and allergic disease. Identifying the key pathogenic factors, determining their relative importance, and understanding their interplay is challenging. Animal models have several advantages over human subjects or in vitro models when studying complex disease states. Genetic and microbiota variations can be eliminated, dietary compliance can be ensured, and access to cells and tissues other than peripheral blood or cell lines allows a more comprehensive understanding of the condition and an opportunity to investigate tissue-specific phenotypes.

In many cases, interactions between immune cells and nonhematopoietic cells are essential for maintaining overall tissue homeostasis, and disruption of this communication may have critical importance in the pathogenesis of disease. For example, it is posited that infants become sensitized to food allergens, rather than develop tolerance, in part because of the immaturity of their gut tissues and altered interactions between intestinal epithelial cells and the immune system. The gastrointestinal tract of newborn mice closely resembles that of pre-term human babies and thus is often used in studies of gastrointestinal function ${ }^{2,3}$. Generation of bone marrow chimeras allows mixing and matching of recipient and bone marrow donors so that the role of hematopoietic and non-hematopoietic components can be studied alone or in combination, and in mice with a fixed genetic background without the 3 -year delay incurred by completing 20 backcrosses $^{4}$. The interactions between hematopoietic and non-hematopoietic cells often shape the nature and magnitude of immune responses, which can have long-term consequences on overall health.

We sought to establish an experimental protocol that allows complete hematopoietic reconstitution of newborn immunocompetent mice so that the relative contribution of hematopoietic and nonhematopoietic lineages could be evaluated during the perinatal period using any wild type or genetically modified strain as the donor or host. Hematopoietic cells can be efficiently transplanted into unirradiated immunodeficient fetal or neonatal mice ${ }^{5-8}$. Complete reconstitution of wild type mice requires pre-conditioning, regardless of the age of the

Laboratory of Allergic Diseases, National Institute of Allergy and Infectious Diseases, National Institutes of Health, Bethesda, MD, USA. Correspondence and requests for materials should be addressed to K.L. (email: KLaky@niaid. nih.gov) 


\begin{tabular}{|l|l|l|l|}
\hline $\begin{array}{l}\text { Age of } \\
\text { treatment }\end{array}$ & Dose rads & $\begin{array}{l}\text { Survived to } \\
\text { weaning }\end{array}$ & $\begin{array}{l}\text { Reconstituted ( } \mathbf{1 0} \% \text { donor } \\
\text { BM at 8 wk post reconstitution) }\end{array}$ \\
\hline \multirow{5}{*}{ Neonate } & 0 & $7 / 7$ & N/A \\
\cline { 2 - 4 } & 0 & $9 / 9$ & $0 / 9$ \\
\cline { 2 - 4 } & 300 & $6 / 6$ & $6 / 6$ \\
\cline { 2 - 4 } & 400 & $5 / 5$ & $2 / 5$ \\
\cline { 2 - 4 } & 500 & $5 / 5$ & $5 / 5$ \\
\cline { 2 - 4 } & 750 & $9 / 9$ & $7 / 9$ \\
\cline { 2 - 4 } & 900 & $19 / 20$ & $14 / 14$ \\
\cline { 2 - 4 } & 1000 & $10 / 10$ & $5 / 6$ \\
\hline \multirow{2}{*}{ adult } & 900 & $16 / 16$ & $16 / 16$ \\
\cline { 2 - 4 } & 1000 & $13 / 13$ & $13 / 13$ \\
\hline
\end{tabular}

Table 1. Survival and reconstitution rates. Two day old (neonate) or adult ( $>5$ weeks) wild type 129SvE mice (CD45.2) were exposed to increasing doses of gamma-irradiation ranging from 0 to 1000 rads. Following irradiation at the age and dose indicated, mice were reconstituted with CD $45.1^{+}$congenic total bone marrow cells.

recipient $^{8-10}$ or the donor ${ }^{11,12}$. Numerous conditioning regimens have been tried, alone or in combination, with varying degrees of success including irradiation, cytokines ${ }^{13}$, antibodies ${ }^{14-18}$, DNA synthesis inhibitors ${ }^{13}$, and alkylating agents ${ }^{19}$. Taking into account previous data on mortality, frequency of mice with detectable donor cells, and the frequency of donor cells among total $\mathrm{CD} 45^{+}$, as well as practical considerations such as time, expense, special training, and side effects, we chose to optimize an irradiation regimen.

\section{Results}

During murine embryonic development, fetal liver is the primary source of hematopoietic progenitors. For a brief time during the perinatal period the liver continues to be a source of extra-medullary hematopoiesis until eventually the bone marrow is fully established and takes over ${ }^{20}$. We reasoned that donor bone marrow injected into the liver of lethally irradiated newborn mice should be able to seed primary lymphoid organs and eventually populate the peripheral immune system of wild type mice.

A harem breeder cage was established with 3 dams and 1 sire. Harem breeder cages were used rather than 1:1 breeder set-ups to eliminate differences in microbiota ${ }^{21}$. Dams were pulled from the harem cage when they appeared pregnant ( E12-14) and a new dam was added to the harem cage. Individually housed pregnant females were checked daily for new births. The first morning that pups were noted was designated Day 0 . If a single sex of recipients is desired, male and female pups of all strains can be distinguished based upon anogenital distance ${ }^{22}$ or via PCR using DNA isolated from tail snips ${ }^{23}$. Alternatively, in pigmented strains, a dark spot is visible in the perineum area of male pups, but absent in females ${ }^{24}$.

Hematopoietic reconstitution of wild type mice requires preconditioning. In the absence of irradiation long-term engraftment of donor cells in wild type recipients occurs only rarely and is usually incomplete ${ }^{8,10,25}$. Lethal irradiation of adult mice is achieved with $8.5 \mathrm{G}^{26}$. There are reports in the literature of neonates exposed to $\leq 600$ rads surviving without reconstitution ${ }^{11,27}$. To determine the optimal dose of lethal irradiation for neonates, 2 day old wild type 129 SvE pups (CD45.2) were exposed to increasing doses of gamma-irradiation, ranging from 300 to 1000 rads, using a cesium-137 source irradiator. To provide warmth and to minimize external odors from being transferred to pups during transport or irradiation, pups were placed in an irradiator pie along with a soiled nestlet and bedding material from their original cage. Two day old neonatal mice tolerated irradiation well. At 8 weeks of age, $\leq 15 \%$ mortality was observed for any of the doses of irradiation evaluated (Table 1 ). One litter of mice exposed to 900 rads and reconstituted on day 2 was allowed to age; 5 of 5 survived past 20 weeks.

Immediately following irradiation, pups were reconstituted with bone marrow cells harvested from CD45.1 congenic mice. Use of a congenic marker allows donor cells to be distinguished from residual host cells. The appropriate choice of congenic marker depends on the cell lineage(s) of interest. Expression variants of leukocyte common antigen (LCA, Ly5, CD45), CD45.1 and CD45.2, allow most leukocyte cell lineages to be distinguished by flow cytometry. Other strategies commonly employed to evaluate chimerism include ubiquitous markers such as sex chromosomes ${ }^{28,29}$, glucose phosphate isomerase or phosphoglycerate kinase isozymes ${ }^{8,10,19,30,31}$; Thy1.1 and Thy1.2 for T cells ${ }^{32}$; allelic variants of immunoglobulin for B cells ${ }^{18}$, or hemoglobin for erythrocytes ${ }^{11,31,33}$.

To eliminate the variable of cell dose, a saturating dose of bone marrow was injected. Seminal studies from the Weissman laboratory established that $1 \times 10^{6}$ total bone marrow cells is sufficient to rescue $\geq 95 \%$ of lethally irradiated adult mice ${ }^{26}$. The maximum volume that could be accommodated by the liver of a 2-day old mouse was $30 \mu \mathrm{l}$. Bone marrow cells were harvested from the femurs of adult CD45.1 congenic mice. On average, $5 \pm 1 \times 10^{7}$ live bone marrow cells were recovered from each donor mouse. Cells were resuspended at $\geq 3 \times 10^{7}$ cells $/ \mathrm{ml}$ in sterile $1 \mathrm{X}$ phosphate buffered saline (PBS) so that $30 \mu \mathrm{l}$ of inoculum would contain $\geq 6 \times 10^{6} \mathrm{BM}$ cells, which was $>5$-times excess of saturation. The inoculum was filtered through sterile $50 \mu \mathrm{M}$ nylon mesh. To allow efficient loading of the syringe and account for dead space within the syringe and the needle, $\geq 50 \mu$ l bone marrow cells were prepared for each intended recipient.

To perform the intra-hepatic (i.h.) injections, 3 pups at a time were sedated by cold. A square of sterile gauze was placed on top of wet ice. Pups were placed on top of the gauze until gross movement ceased, which took approximately 5 minutes. Each pup was lightly scruffed on the back in the shoulder area and held in a supine position to visualize the abdomen. The stomach of nursing pups appears as a large milky white spot on the right side 
A.

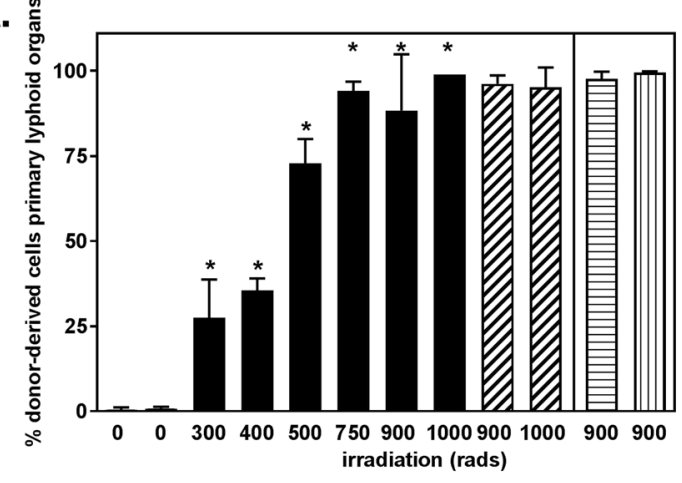

B.

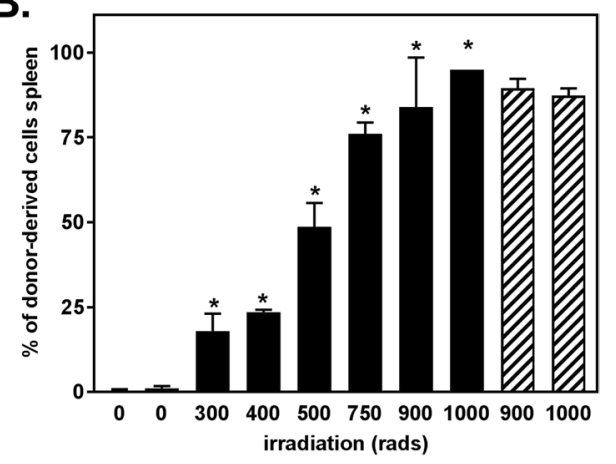

Figure 1. Donor cell reconstitution is positively correlated with the dose of irradiation. Wild type 129SvE mice (CD45.2) were exposed to increasing doses of gamma-irradiation, from 0 to 1000 rads. Following irradiation at the dose indicated, pups were intra-hepatically (i.h.) injected with CD45.1 ${ }^{+}$congenic bone marrow cells. (A) The frequency of CD45.1 ${ }^{+}$donor-derived cells in primary lymphoid organs of reconstituted mice was determined 5-8 weeks post irradiation and reconstitution. White, black, and diagonally striped bars to the left of the line are bone marrow. White bar is bone marrow of unirradiated and uninjected control mice. Black bars are bone marrow of pups irradiated and injected at 2 days of age. Diagonally striped bars are bone marrow from mice irradiated and injected with congenic bone marrow as adults. Bars to the right of the line are thymus from mice irradiated and injected with bone marrow at 2 days of age (horizontal lines) or as adults (vertical lines). Data shown are the mean $\pm S D$ of $2-10$ mice analyzed individually. $* \mathrm{p}<0.05$, Dunnett's multiple comparisons test. (B) The frequency of CD45.1+ donor-derived splenocytes in reconstituted mice was determined 5-8 weeks post irradiation and reconstitution. White bar is spleen from age matched unirradiated and uninjected control mice. Black bars are pups irradiated and injected at 2 days of age. Striped bars are spleen from mice irradiated and injected with bone marrow as adults. Data shown are the mean \pm SD of 2-10 mice analyzed individually. $* \mathrm{p}<0.05$, Dunnett's multiple comparisons test.

of the abdomen. To the left and slightly above the stomach, the liver appears as a large reddish organ just below the rib cage. Using a $0.3 \mathrm{cc}$ syringe with a 29 gauge $1 / 2^{\prime \prime}$ needle, $1 \times 10^{6}$ bone marrow cells resuspended in $30 \mu \mathrm{l}$ of sterile 1X PBS were injected i.h. The needle was inserted bevel up to allow visualization of the inoculum being injected. After the proper volume was dispensed, to prevent backflow the needle was held in place for a few seconds before being withdrawn slowly. Sterile gauze was used to apply gentle pressure to the injection site for several seconds. Pups were wrapped in nestlet material from their original cage, placed on top of a warming pad until movement resumed, and then were returned to their mother where they remained until weaning at 21 days of age. If a dam was not immediately attentive to the returning pups, the pups were marked with the dam's scent by encouraging her to urinate on to the pups or on to the investigator's gloved hands which were then used to rub the pups' skin.

Mice were analyzed to determine the extent of hematopoietic reconstitution (Table 1). Studies have traditionally defined engraftment as $>1 \%$ donor cells in peripheral blood ${ }^{14,34}$. We set a more rigorous standard and defined reconstitution as $>10 \%$ donor-derived cells in the bone marrow at 5-8 weeks post-reconstitution, a timepoint when bone marrow and peripheral cells have achieved steady state ${ }^{35-37}$. No donor-derived cells were detected in animals that received i.h. injection in the absence of irradiation. Donor-derived cells were observed in all mice irradiated prior to i.h. injection. The extent of donor cell reconstitution in bone marrow and spleen were positively correlated with the dose of irradiation (Fig. 1A,B).

Proliferating cells are most susceptible to the effects of irradiation and during the first week of life extensive proliferation occurs in multiple organ systems. Neonatal exposure to high dose irradiation impairs growth which manifests as a decrease in linear height and an overall decrease in body size ${ }^{34,38-40}$. Mice receiving higher doses of irradiation appeared smaller than controls (Fig. 2A). We weighed mice 5-8 wk after irradiation and observed that the overall size of the mice varied inversely with the dose of irradiation (Fig. 2B). Consistent with previous studies characterizing the effects of early life exposure to irradiation on growth ${ }^{38,40}$, at 8 weeks of age mice that had been exposed to $\geq 500$ rads as a neonate were significantly smaller than non-irradiated, age- and sex-matched control animals $(\mathrm{p}<0.01)$.

Despite being small, neonatally irradiated and reconstituted mice appeared overall healthy, walked with a normal gait, had normal dentition, and maintained an agouti coat color (Fig. 2A). The mass of primary and secondary lymphoid tissues and non-hematopoietic organs were proportionately decreased (Fig. $2 \mathrm{C}$ and ${ }^{38}$ ). In addition to weighing the organs, we made single cell suspensions. The number of total live leukocytes in spleen or thymus did not differ significantly between mice irradiated and reconstituted on day 2 and unmanipulated controls $(\mathrm{p}=0.14$ and $\mathrm{p}=0.63$, respectively) (Fig. 2D). The thymus of mice irradiated and reconstituted at 8 weeks of age and then analyzed 8 weeks post-reconstitution at 16 weeks of age had slightly fewer thymocytes and slightly more splenocytes, but the differences did not reach statistical significance $(\mathrm{p}=0.24$ and $\mathrm{p}=0.26$, respectively).

We analyzed the cellular composition of donor-derived $\left(\mathrm{CD} 45.1^{+}\right)$cells in the bone marrow, thymus, and spleen of mice that had been irradiated with 900 rads and reconstituted with bone marrow 8 weeks prior (Fig. 3). The frequency of lymphoid and myeloid lineage cells in bone marrow was indistinguishable from unirradiated age- and sex-matched control animals or adult irradiated and reconstituted mice. There were no significant 
A.

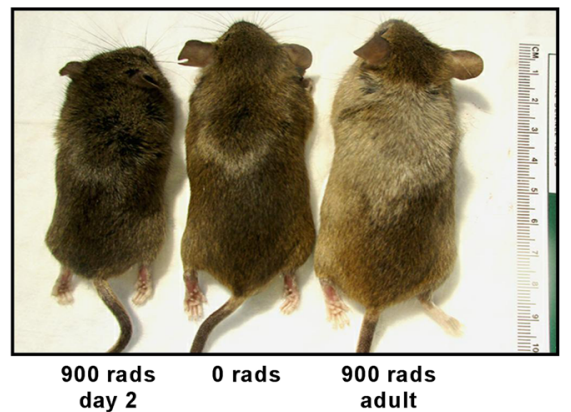

B.

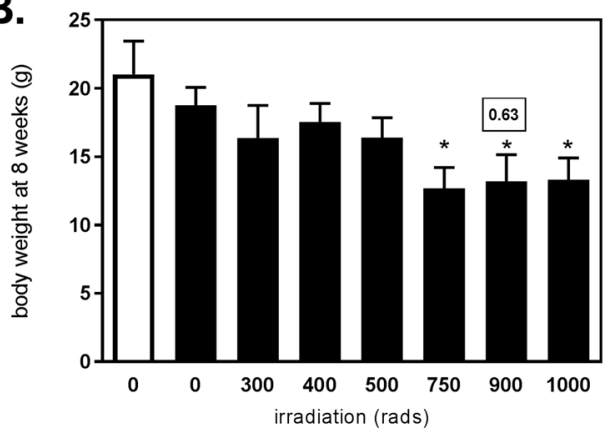

C.

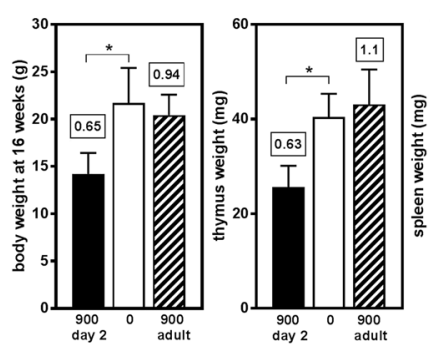

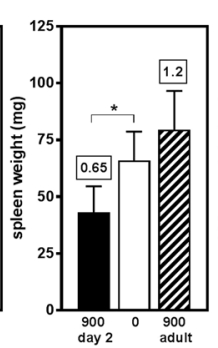
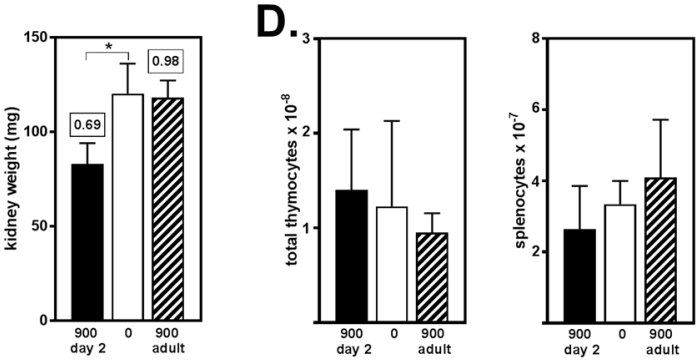

Figure 2. Total body irradiation impairs growth. (A) 8 week old mice that had been neonatally irradiated with 900 rads ( 900 rads day 2 ) were smaller than unirradiated adult mice ( 0 rads) and irradiated adult mice (900 rads adult), but appeared overall healthy and maintained an agouti coat color. (B) The total body weight of 5-8 week old mice that had received $\geq 500$ rads on day was significantly less than non-irradiated, age- and sex-matched control animals. White bar is age-matched unirradiated and uninjected control mice. Solid bars are pups irradiated and injected at 2 days of age. Data shown are the mean $\pm \mathrm{SD}$ of $>4$ mice per group, analyzed individually. Text box above the bar for $900 \mathrm{rads}$ on day $2=$ (mean experimental/ mean unmanipulated controls). ${ }^{*} \mathrm{p}<0.05$, Dunnett's multiple comparisons test. (C) Primary and secondary lymphoid tissues and non-hematopoietic organs were proportionately decreased in size of 16-20 week old mice that had received 900 rads on day 2 (black bar) as compared to non-irradiated, age- and sex-matched control animals (white bar). In contrast, there were no significant differences between mice irradiated with 900 rads and reconstituted as adults (diagonally striped bar) and non-irradiated control animals (white bar). Data shown are the mean $\pm S D$ of $>4$ mice per group, analyzed individually. Numbers in boxes above the bars = (mean experimental/ mean unmanipulated controls). *p $<0.05$, Dunnett's multiple comparisons test. (D) The number of total live leukocytes isolated from spleen or thymus did not differ significantly between irradiated and reconstituted mice and unmanipulated controls. Data shown are the mean $\pm \mathrm{SD}$ of $\mathrm{N} \geq 9$ mice per group, analyzed individually 8-9 weeks post-reconstitution or 12-16 weeks of age.

differences in the frequency of immature $\left(\mathrm{CD} 4^{-} \mathrm{CD} 8^{-}, \mathrm{CD} 4^{+} \mathrm{CD} 8^{+}\right)$or mature $\mathrm{T}$ cell subsets $\left(\gamma \delta, \mathrm{CD} 4^{+} \alpha \beta^{+}\right.$, $\mathrm{CD}^{+} \alpha \beta^{+}$) in the thymus of neonatally irradiated and reconstituted mice when compared to unirradiated controls or adult irradiated and reconstituted mice. The relative contributions of mature $\mathrm{T}$ cell, $\mathrm{B}$ cell, and myeloid lineage cells in the spleen were also indistinguishable from unmanipulated controls or adult irradiated and reconstituted mice.

Most animals exposed to total body irradiation have some residual host cells. Hematopoietic cells differ in radiosensitivity ${ }^{41,42}$. Most residual host cells in the lymphoid organs of lethally irradiated animals are radioresistant mature T cells (Supplementary Fig. 1A,B and ${ }^{12,43-46}$. In contrast, B cells, eosinophils, and CD $4^{+} \mathrm{CD} 8^{+}$ thymocytes are so radio-sensitive that exposure to even a sublethal dose of irradiation is sufficient to eliminate host-derived cells ${ }^{42,47,48}$. Several mechanisms may contribute to radio-resistance including cell cycle status at the time of irradiation, expression of anti-apoptotic genes, lineage/tissue specific tissue niches ${ }^{46,49}$.

\section{Discussion}

In summary, we describe a protocol that consistently results in highly efficient hematopoietic reconstitution of lymphoid and myeloid lineages in immunocompetent neonatal mice. In contrast to antibody depleting regimens $^{16-18}$ or chemotherapeutic regimens such as 5-fluorouracil or Busulfan ${ }^{8,13}$ the protocol is both cost and time efficient while consistently achieving nearly $100 \%$ survival with $>75 \%$ donor engraftment. Compared to intrauterine injection protocols which involve survival surgery and result in high mortality rates ${ }^{8,10,14,25}$, the method that we describe requires minimal advanced training, has excellent survival rates, and does not require timed pregnant females.

Irradiation is commonly used for pre-transplant conditioning. However, total body irradiation is not without consequence $^{50}$. Tissues with highly proliferative cells are most the most impacted. In neonates this includes long bones $^{40,51}$. Exposure to total body irradiation is associated with decreased stature across species ${ }^{34,38,39,52,53}$. It is generally agreed that growth impairment correlates directly with the dose of irradiation and inversely with the age 

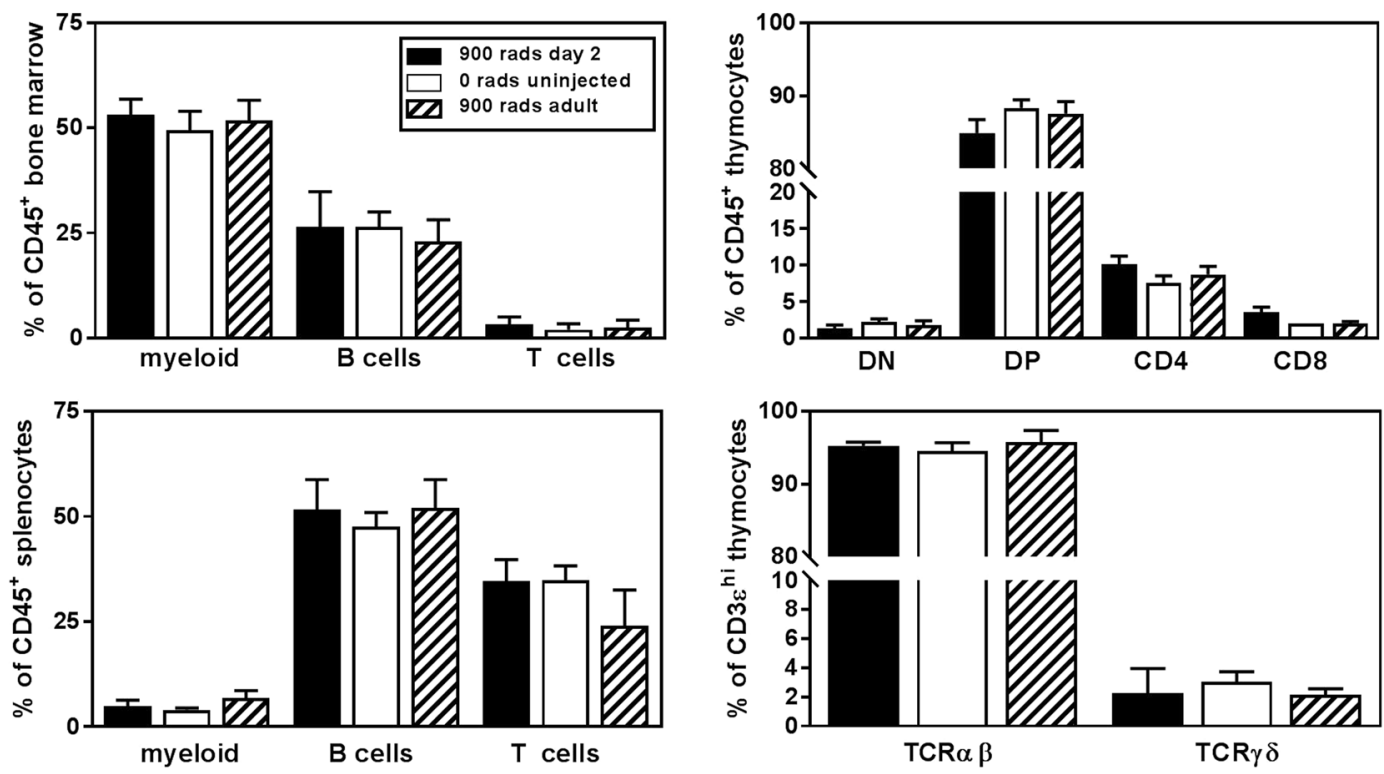

Figure 3. In 8 week old mice that had been neonatally irradiated with 900 rads (black bars), the relative contributions of donor derived B cell $\left(\mathrm{CD} 45.1^{+} \mathrm{CD} 19^{+}\right)$and myeloid lineage cells $\left(\mathrm{CD} 45.1^{+} \mathrm{CD} 11 \mathrm{~b}^{+}\right)$ developing in the bone marrow were indistinguishable from unmanipulated controls (white bars) or donor derived cells in adult irradiated and reconstituted mice (hatched bars); the relative composition of donor derived mature $\mathrm{T}\left(\mathrm{CD} 45.1^{+} \mathrm{CD} 3 \varepsilon^{+}\right), \mathrm{B}\left(\mathrm{CD} 45.1^{+} \mathrm{CD} 19^{+}\right)$, and myeloid $\left(\mathrm{CD} 45.1^{+} \mathrm{CD} 11 \mathrm{~b}^{+}\right)$splenocytes was the same. The frequency of donor derived $\mathrm{T}$ cell subsets in the thymus was unperturbed in 8 week old mice that had been neonatally irradiated with 900rads; double negative, $\mathrm{DN}\left(\mathrm{CD} 45.1^{+} \mathrm{CD} 4^{-} \mathrm{CD} 8 \alpha^{-}\right)$; double positive, $\mathrm{DP}$ $\left(\mathrm{CD} 45.1^{+} \mathrm{CD}^{+} \mathrm{CD} 8 \alpha^{+}\right)$; $\mathrm{CD} 4$ single positive, $\mathrm{CD} 4 \mathrm{SP}\left(\mathrm{CD} 45.1^{+} \mathrm{TCR} \beta^{\text {hi }} \mathrm{CD} 44^{+} \mathrm{CD} 8 \alpha^{-}\right)$; $\mathrm{CD} 8$ single positive, CD8 SP (CD45.1 $1^{+}$TCR $\beta^{\text {hi }}$ CD 4 CD $\left.8 \alpha^{+}\right)$; TCR $\alpha \beta\left(C D 45.1^{+} \mathrm{CD} 3 \varepsilon^{\text {hi }}\right.$ TCR $\left.\beta^{+}\right)$; and TCR $\gamma \delta\left(C D 45.1^{+}\right.$CD $3 \varepsilon^{\text {hi }}$ $\left.\mathrm{TCR} \delta^{+}\right)$. Data shown are the mean $\pm \mathrm{SD}$ of $\geq 5$ mice per group, analyzed individually.

of exposure ${ }^{40,54}$. The mechanism(s) by which high dose irradiation stunts growth are not completely understood and are likely multifactorial. For instance, it has been posited that irradiation impairs growth hormone secretion. However, there is poor correlation between growth hormone levels and growth impairment in long term survivors $^{52,53}$. Irradiation can damage epiphyseal growth plates which compromises bone growth including vertebrae, ribs, and leg bones ${ }^{5-58}$. To control for the pleiotropic effects of irradiation, it is essential to include the appropriate experimental controls, such as irradiated neonates reconstituted with syngeneic bone marrow.

The protocol was optimized by using unfractionated adult bone marrow as a source of progenitors because donors were readily available, and the number of donor cells was not a limiting factor which allowed a range of irradiation doses to be evaluated. Fetal liver or purified stem cells could also be used as a source of hematopoietic precursors. Data obtained from studies designed to directly compare the repopulation potential of different precursors have concluded that the repopulation potential of 500 hematopoietic stem cells (Lineage ${ }^{\text {neg }}$ Thy $1^{\text {lo }}$ Sca $1^{+}$) or $\sim 1.5 \times 10^{4}$ total embryonic day 14.5 fetal liver cells is comparable to $1 \times 10^{6}$ total adult bone marrow cells ${ }^{12,26,59}$. Detailed protocols for isolating hematopoietic stem cells from fetal or adult tissues and the expected frequency of precursors from different tissues at different ages are reviewed $\mathrm{in}^{60}$. The system is also amenable to making mixed chimeras, which are a powerful tool to study regulatory relationships and/or competitive fitness.

This system allows us to identify, manipulate, and evaluate hematopoietic and non-hematopoietic elements that are hypothesized to influence the development of multiple disease states, at developmentally relevant time points, and in an experimental system that takes into account the variables of genetics, microbiota, and diet. It alleviates the need to use immuno-deficient recipients, while still allowing the study of events occurring during the perinatal period. Cutaneous exposure to food antigen during the neonatal period is correlated with an increased risk of allergic sensitization ${ }^{61-63}$. Colonization of the gut occurs in the neonatal period, and the intestinal microbiome may influence susceptibility to food allergy ${ }^{64-66}$. The model we described will be a powerful tool to evaluate the role of microbiota and Toll-like receptors (TLRs) in allergic sensitization. TLRs, which are expressed on both hematopoietic and non-hematopoietic cells, are pattern recognition receptors that sense bacterial products. Neonatal mice reconstituted with TLR4-deficient bone will help to determine whether the increase in TLR4 ${ }^{+}$cells in the intestinal lamina propria of children with food allergy has physiological relevance ${ }^{67}$. TLR4-deficient mice reconstituted with WT bone marrow can be used to determine how TLR4 expression on keratinocytes or intestinal epithelial cells influences food allergy ${ }^{68,69}$. TLR9 agonists may have both prophylactic and therapeutic value for the treatment of peanut allergy $\mathrm{y}^{70-72}$. Reconstituting TLR9 deficient neonates ${ }^{73}$ with WT bone marrow, or WT neonates with TLR9-deficient bone marrow, should reveal whether TLR9 expression on hematopoietic cells and/or non-hematopoietic cells (such as epithelial cells) plays a role in allergy versus tolerance to food antigens $\mathrm{s}^{74,75}$. Understanding the cellular mechanisms involved in food allergy versus oral tolerance will help to optimize therapies for food allergy. 
The focus of our studies is food allergy, but this model is well suited for studying any condition or organ system in which critical developmental changes occur during the postnatal period. For example, early life exposures are linked to airway disease later in life, and like the GI tract, the respiratory tract also undergoes critical changes during the post-natal period ${ }^{76,77}$. Brain structures like the cerebellum and hippocampus develop postnatally in mice and humans ${ }^{78}$, and thus the model system described here could be used to test hypotheses that postnatal inflammation and responses to infection impact the development of neuro-psychiatric conditions in adulthood such as autism, schizophrenia, depression, anxiety, obesity, and sleep disorders ${ }^{79}$. Clinical data show that there are sex-associated differences in disease course and prognosis of newborn ${ }^{80}$. Reconstituting female neonates with bone marrow from male donors, and the converse, would help distinguish between environmental (hormonal effects) and immune cell intrinsic effects conferred by genes located on the sex chromosomes including TLRs, several cytokine receptors, and Foxp $3^{81}$. Thus, this methodology may have significant utility in efforts to unravel the complexity of the perinatal factors that influence long-term health.

\section{Methods}

Mice. 129SvE (CD45.2) mice were obtained from the NIAID breeding contract at Taconic Farms and then bred in our animal facility. Mice were maintained under specific-pathogen-free conditions. All experiments were performed in compliance with the protocols and regulations of NIAID's Animal Care and Use Committee who approved this study (Animal Study Protocol \#LAD-11E).

Flow Cytometry. Thymus and spleens were harvested in Media 199 supplemented with $10 \%$ fetal calf serum, $0.2 \mathrm{mM}$ L-glutamine, 100 units $/ \mathrm{mL}$ of penicillin, $100 \mu \mathrm{g} / \mathrm{mL}$ of streptomycin, and $250 \mathrm{ng} / \mathrm{mL}$ of Amphotericin B. Bone marrow cells were flushed from femurs. Single-cell suspensions were made by passing cells through $100 \mu \mathrm{M}$ nylon mesh.

For surface staining, cells were resuspended in Hank's Balanced Salt Solution supplemented with $0.1 \%$ bovine serum albumin $+0.1 \% \mathrm{NaN}_{3}$ and properly diluted antibodies. Live cells were gated based on exclusion of 7-Aminoactinomycin D. Data were collected on a LSR Fortessa cell analyzer and then analyzed in FlowJo (Treestar).

Antibodies used were: anti-mouse CD16/32 (2.4G2), CD45.1 (A20), CD45.2 (104), CD11b (M1/70.15), CD3 (17A2), CD19 (1D3), TCR $\beta$ (H57-597), TCR $\gamma \delta$ (GL3), CD4 (RMA4-5), and CD8 $\alpha$ (53-6.7).

Statistics. Statistical significance between groups was determined using unpaired two-tailed Student's $t$-tests or Dunnett's multiple comparison tests in GraphPad, PRISM. Probability values $<0.05$ were considered statistically significant.

Ethical approval. The authors declare that all experimental protocols were approved by the National Institute of Allergy and Infectious Diseases' Animal Care and Use Committee and were carried out in accordance with all rules and regulations stipulated by the National Institutes of Health Office of Laboratory Animal Welfare.

\section{References}

1. Hanson, M. A. \& Gluckman, P. D. Early developmental conditioning of later health and disease: physiology or pathophysiology? Physiol. Rev. 94, 1027-1076, https://doi.org/10.1152/physrev.00029.2013 (2014).

2. McCracken, V. J. \& Lorenz, R. G. The gastrointestinal ecosystem: a precarious alliance among epithelium, immunity and microbiota. Cell. Microbiol. 3, 1-11 (2001).

3. Tatum, P. M. Jr., Harmon, C. M., Lorenz, R. G. \& Dimmitt, R. A. Toll-like receptor 4 is protective against neonatal murine ischemiareperfusion intestinal injury. J Ped. Surg. 45, 1246-1255, https://doi.org/10.1016/j.jpedsurg.2010.02.093 (2010).

4. Green, E. L. Genetics and probability in animal breeding experiments: a primer and reference book on probability, segregation, assortment, linkage and mating systems for biomedical scientists who breed and use genetically defined laboratory animals for research. (Oxford University Press, 1981).

5. Awong, G. \& Zuñiga-Pflücker, J. C. Generation, isolation, and engraftment of in vitro-derived human T cell progenitors. Meth. Mol. Biol. 946, 103-113, https://doi.org/10.1007/978-1-62703-128-8_7 (2013).

6. Pearson, T., Greiner, D. L. \& Shultz, L. D. Creation of "humanized" mice to study human immunity. Curr. Protoc. Immunol. Chapter 15, Unit 15 21, https://doi.org/10.1002/0471142735.im1521s81 (2008).

7. Waskow, C. et al. Hematopoietic stem cell transplantation without irradiation. Nat. Meth. 6, 267-269, https://doi.org/10.1038/ nmeth.1309 (2009).

8. Howson-Jan, K., Matloub, Y. H., Vallera, D. A. \& Blazar, B. R. In utero engraftment of fully H-2-incompatible versus congenic adult bone marrow transferred into nonanemic or anemic murine fetal recipients. Transplantation 56, 709-716 (1993).

9. Billingham, R. E., Brent, L. \& Medawar, P. B. Actively acquired tolerance of foreign cells. Nature 172, 603-606 (1953).

10. Carrier, E., Lee, T. H., Busch, M. P. \& Cowan, M. J. Induction of tolerance in nondefective mice after in utero transplantation of major histocompatibility complex-mismatched fetal hematopoietic stem cells. Blood 86, 4681-4690 (1995).

11. Harrison, D. E. Long-term erythropoietic repopulating ability of old, young, and fetal stem cells. J. Exp. Med. 157, 1496-1504 (1983).

12. Szilvassy, S. J., Meyerrose, T. E., Ragland, P. L. \& Grimes, B. Differential homing and engraftment properties of hematopoietic progenitor cells from murine bone marrow, mobilized peripheral blood, and fetal liver. Blood 98, 2108-2115 (2001).

13. van Os, R., Dawes, D., Mislow, J. M., Witsell, A. \& Mauch, P. M. Host conditioning with 5-fluorouracil and kit-ligand to provide for long-term bone marrow engraftment. Blood 89, 2376-2383 (1997).

14. Derderian, S. C. et al. In utero depletion of fetal hematopoietic stem cells improves engraftment after neonatal transplantation in mice. Blood 124, 973-980, https://doi.org/10.1182/blood-2014-02-550327 (2014).

15. Wulf, G. G., Luo, K. L., Goodell, M. A. \& Brenner, M. K. Anti-CD45-mediated cytoreduction to facilitate allogeneic stem cell transplantation. Blood 101, 2434-2439, https://doi.org/10.1182/blood-2002-08-2379 (2003).

16. Czechowicz, A., Kraft, D., Weissman, I. L. \& Bhattacharya, D. Efficient transplantation via antibody-based clearance of hematopoietic stem cell niches. Science 318, 1296-1299, https://doi.org/10.1126/science.1149726 (2007).

17. Leong, L. Y., Qin, S., Cobbold, S. P. \& Waldmann, H. Classical transplantation tolerance in the adult: the interaction between myeloablation and immunosuppression. Eur. J. Immunol. 22, 2825-2830, https://doi.org/10.1002/eji.1830221111 (1992).

18. Qin, S. X., Cobbold, S., Benjamin, R. \& Waldmann, H. Induction of classical transplantation tolerance in the adult. J. Exp. Med. 169, 779-794 (1989). 
19. Down, J. D., Westerhof, G. R., Boudewijn, A., Setroikromo, R. \& Ploemacher, R. E. Thiotepa improves allogeneic bone marrow engraftment without enhancing stem cell depletion in irradiated mice. Bone Marrow Transplant. 21, 327-330, https://doi. org/10.1038/sj.bmt.1701103 (1998).

20. Wolber, F. M. et al. Roles of spleen and liver in development of the murine hematopoietic system. Exp. Hematol. 30, 1010-1019 (2002).

21. Moore, R. J. \& Stanley, D. Experimental design considerations in microbiota/inflammation studies. Clin. Trans. Immunol. 5, e92, https://doi.org/10.1038/cti.2016.41 (2016).

22. Schneider, J. E., Wysocki, C. J., Nyby, J. \& Whitney, G. Determining the sex of neonatal mice (Mus musculus). Behavior Res. Meth. Instrument. 10, 105-105, https://doi.org/10.3758/bf03205110 (1978).

23. Deeney, S., Powers, K. N. \& Crombleholme, T. M. A comparison of sexing methods in fetal mice. Lab Anim. 45, 380-384, https://doi. org/10.1038/laban.1105 (2016).

24. Wolterink-Donselaar, I. G., Meerding, J. M. \& Fernandes, C. A method for gender determination in newborn dark pigmented mice. Lab Anim. 38, 35-38, https://doi.org/10.1038/laban0109-35 (2009).

25. Blazar, B. R. et al. Engraftment of severe combined immune deficient mice receiving allogeneic bone marrow via In utero or postnatal transfer. Blood 92, 3949-3959 (1998).

26. Uchida, N., Aguila, H. L., Fleming, W. H., Jerabek, L. \& Weissman, I. L. Rapid and sustained hematopoietic recovery in lethally irradiated mice transplanted with purified Thy-1.1lo Lin-Sca-1+ hematopoietic stem cells. Blood 83, 3758-3779 (1994).

27. Sasaki, S. \& Fukuda, N. Dose-response relationship for induction of ovarian tumors in mice irradiated during prenatal, early postnatal and elder periods. J. Radiat. Res. 49, 623-633 (2008).

28. Peters, S. O., Bauermeister, K., Simon, J. P., Branke, B. \& Wagner, T. Quantitative polymerase chain reaction-based assay with fluorogenic Y-chromosome specific probes to measure bone marrow chimerism in mice. J Immunol. Meth. 260, 109-116 (2002).

29. Ogata, H. et al. Long-term repopulation of hematolymphoid cells with only a few hemopoietic stem cells in mice. Proc. Natl. Acad. Sci. USA 92, 5945-5949 (1995).

30. Boer, P. H. et al. Polymorphisms in the coding and noncoding regions of murine Pgk-1 alleles. Biochem. Genet. 28, 299-308 (1990).

31. Yoder, M. C., Cumming, J. G., Hiatt, K., Mukherjee, P. \& Williams, D. A. A novel method of myeloablation to enhance engraftment of adult bone marrow cells in newborn mice. Biol. Blood Marrow Transplant. 2, 59-67 (1996).

32. Spangrude, G. J. \& Scollay, R. Differentiation of hematopoietic stem cells in irradiated mouse thymic lobes. Kinetics and phenotype of progeny. J. Immunol. 145, 3661-3668 (1990).

33. Down, J. D., Tarbell, N. J., Thames, H. D. \& Mauch, P. M. Syngeneic and allogeneic bone marrow engraftment after total body irradiation: dependence on dose, dose rate, and fractionation. Blood 77, 661-669 (1991).

34. Arora, N. et al. Effect of developmental stage of HSC and recipient on transplant outcomes. Dev. Cell 29, 621-628, https://doi. org/10.1016/j.devcel.2014.04.013 (2014)

35. Li, C. L. \& Johnson, G. R. Long-term hemopoietic repopulation by Thy-1lo, Lin-, Ly6A/E+ cells. Exp. Hematol. 20, 1309-1315 (1992).

36. Filip, S. et al. The peripheral chimerism of bone marrow-derived stem cells after transplantation: regeneration of gastrointestinal tissues in lethally irradiated mice. J. Cell. Mol. Med. 18, 832-843, https://doi.org/10.1111/jcmm.12227 (2014).

37. Down, J. D. \& Ploemacher, R. E. Transient and permanent engraftment potential of murine hematopoietic stem cell subsets: differential effects of host conditioning with gamma radiation and cytotoxic drugs. Exp. Hematol. 21, 913-921 (1993).

38. Gajewski, A. K., Slowikowska, M. G. \& Grzymala, W. J. Late effects of irradiation of newborn mice with gamma rays. II. Changes in peripheral blood and the size of internal organs. Rocz. Panstw. Zakl. Hig. 22, 221-229 (1971).

39. Nash, D. J. Effects of neonatal irradiation and genotype on postnatal growth in mice. Biol. Neonate 18, 17-28, https://doi. org/10.1159/000240342 (1971).

40. Gonzalez, D. G. \& van Dijk, J. D. Experimental studies on the response of growing bones to X ray and neutron irradiation. Int. J. Radiat. Oncol. Biol. Phys. 9, 671-677 (1983).

41. Heylmann, D., Rodel, F., Kindler, T. \& Kaina, B. Radiation sensitivity of human and murine peripheral blood lymphocytes, stem and progenitor cells. Biochim. Biophys. Acta 1846, 121-129, https://doi.org/10.1016/j.bbcan.2014.04.009 (2014).

42. Durum, S. K. \& Gengozian, N. The comparative radiosensitivity of T and B lymphocytes. Int. J. Radiat. Biol. Relat. Stud. Phys. Chem. Med. 34, 1-15 (1978).

43. Anderson, R. E. et al. Radiosensitivity of T and B lymphocytes. IV. Effect of whole body irradiation upon various lymphoid tissues and numbers of recirculating lymphocytes. J. Immunol. 118, 1191-1200 (1977).

44. Bosco, N., Swee, L. K., Benard, A., Ceredig, R. \& Rolink, A. Auto-reconstitution of the T-cell compartment by radioresistant hematopoietic cells following lethal irradiation and bone marrow transplantation. Exp. Hematol. 38, 222-232 e222, https://doi. org/10.1016/j.exphem.2009.12.006 (2010).

45. Komatsu, N. \& Hori, S. Full restoration of peripheral Foxp3+ regulatory T cell pool by radioresistant host cells in scurfy bone marrow chimeras. Proc. Natl. Acad. Sci. USA 104, 8959-8964, https://doi.org/10.1073/pnas.0702004104 (2007).

46. Domen, J., Gandy, K. L. \& Weissman, I. L. Systemic overexpression of BCL-2 in the hematopoietic system protects transgenic mice from the consequences of lethal irradiation. Blood 91, 2272-2282 (1998).

47. Szabo, L. G. \& Kelemen, E. Eosinophilic spleen colonies are produced in rat-marrow-transplanted but not in murine-marrowtransplanted mice. Eur. J. Haematol. 41, 347-351 (1988).

48. Huiskamp, R. \& van Ewijk, W. Repopulation of the mouse thymus after sublethal fission neutron irradiation. I. Sequential appearance of thymocyte subpopulations. J. Immunol. 134, 2161-2169 (1985).

49. Jeggo, P. \& Lobrich, M. Radiation-induced DNA damage responses. Radiat. Prot. Dosimetry 122, 124-127, https://doi.org/10.1093/ $\mathrm{rpd} / \mathrm{ncl} 495$ (2006).

50. Paix, A. et al. Total body irradiation in allogeneic bone marrow transplantation conditioning regimens: A review. Crit. Rev. Oncol. Hematol. 123, 138-148, https://doi.org/10.1016/j.critrevonc.2018.01.011 (2018).

51. Cole, H. A. et al. Differential development of the distal and proximal femoral epiphysis and physis in mice. Bone 52, 337-346, https:// doi.org/10.1016/j.bone.2012.10.011 (2013).

52. Borgstrom, B. \& Bolme, P. Growth and growth hormone in children after bone marrow transplantation. Horm. Res. 30, 98-100, https://doi.org/10.1159/000181037 (1988).

53. Shinohara, O. et al. Growth and growth hormone secretion in children after bone marrow transplantation. Acta Paediatr. Jpn. 35, $22-26$ (1993).

54. Rutherford, H. \& Dodd, G. D. Complications of radiation therapy: growing bone. Semin. Roentgenol. 9, 15-27 (1974).

55. Gonzalez, D. G. \& Breur, K. Dose-modifying effect of misonidazole on the radiation response of growing cartilage in mice. Br. J. Cancer Suppl. 3, 235-236 (1978).

56. Parker, R. G. \& Berry, H. C. Late effects of therapeutic irradiation on the skeleton and bone marrow. Cancer 37, 1162-1171 (1976).

57. Probert, J. C., Parker, B. R. \& Kaplan, H. S. Growth retardation in children after megavoltage irradiation of the spine. Cancer 32, 634-639 (1973).

58. Shalet, S. M., Gibson, B., Swindell, R. \& Pearson, D. Effect of spinal irradiation on growth. Arch. Dis. Child. 62, 461-464 (1987).

59. Rebel, V. I., Miller, C. L., Eaves, C. J. \& Lansdorp, P. M. The repopulation potential of fetal liver hematopoietic stem cells in mice exceeds that of their liver adult bone marrow counterparts. Blood 87, 3500-3507 (1996). 
60. Miller, C. L., Dykstra, B. \& Eaves, C. J. Characterization of mouse hematopoietic stem and progenitor cells. Curr. Protoc. Immunol. Chapter 22, Unit 22B 22, https://doi.org/10.1002/0471142735.im22b02s80 (2008).

61. Lack, G. et al. Factors associated with the development of peanut allergy in childhood. N. Engl. J. Med. 348, 977-985, https://doi. org/10.1056/NEJMoa013536 (2003).

62. Lyons, J. J. \& Milner, J. D. Primary atopic disorders. J. Exp. Med. 215, 1009-1022, https://doi.org/10.1084/jem.20172306 (2018).

63. Walker, M. T. et al. Mechanism for initiation of food allergy: Dependence on skin barrier mutations and environmental allergen costimulation. J Allergy Clin. Immunol, https://doi.org/10.1016/j.jaci.2018.02.003 (2018).

64. Stefka, A. T. et al. Commensal bacteria protect against food allergen sensitization. Proc. Natl. Acad. Sci. USA 111, 13145-13150, https://doi.org/10.1073/pnas.1412008111 (2014).

65. Gensollen, T. \& Blumberg, R. S. Correlation between early-life regulation of the immune system by microbiota and allergy development. J Allergy Clin. Immunol. 139, 1084-1091, https://doi.org/10.1016/j.jaci.2017.02.011 (2017).

66. Savage, J. H. et al. A prospective microbiome-wide association study of food sensitization and food allergy in early childhood. Allergy 73, 145-152, https://doi.org/10.1111/all.13232 (2018).

67. Westerholm-Ormio, M., Vaarala, O., Tiittanen, M. \& Savilahti, E. Infiltration of Foxp3- and Toll-like receptor-4-positive cells in the intestines of children with food allergy. J Pediatr. Gastroenterol. Nutr. 50, 367-376, https://doi.org/10.1097/MPG.0b013e3181cd2636 (2010).

68. Brandt, E. B., Gibson, A. M., Bass, S., Rydyznski, C. \& Khurana Hershey, G. K. Exacerbation of allergen-induced eczema in TLR4and TRIF-deficient mice. J. Immunol. 191, 3519-3525, https://doi.org/10.4049/jimmunol.1300789 (2013).

69. Li, X. et al. Toll-like receptor 4 increases intestinal permeability through up-regulation of membrane PKC activity in alcoholic steatohepatitis. Alcohol 47, 459-465, https://doi.org/10.1016/j.alcohol.2013.05.004 (2013).

70. Zhu, F. G., Kandimalla, E. R., Yu, D. \& Agrawal, S. Oral administration of a synthetic agonist of Toll-like receptor 9 potently modulates peanut-induced allergy in mice. J. Allergy Clin. Immunol. 120, 631-637, https://doi.org/10.1016/j.jaci.2007.05.015 (2007).

71. Kulis, M., Gorentla, B., Burks, A. W. \& Zhong, X. P. Type B CpG oligodeoxynucleotides induce Th1 responses to peanut antigens: modulation of sensitization and utility in a truncated immunotherapy regimen in mice. Mol. Nutr. Food Res. 57, 906-915, https:// doi.org/10.1002/mnfr.201200410 (2013).

72. Srivastava, K. D. et al. Investigation of peanut oral immunotherapy with $\mathrm{CpG} /$ peanut nanoparticles in a murine model of peanut allergy. J. Allergy Clin. Immunol. 138, 536-543 e534, https://doi.org/10.1016/j.jaci.2016.01.047 (2016).

73. Hemmi, H. et al. A Toll-like receptor recognizes bacterial DNA. Nature 408, 740-745, https://doi.org/10.1038/35047123 (2000).

74. de Kivit, S. et al. In vitro evaluation of intestinal epithelial TLR activation in preventing food allergic responses. Clin. Immunol. 154, 91-99, https://doi.org/10.1016/j.clim.2014.07.002 (2014)

75. Massaad, M. J. et al. DOCK8 and STAT3 dependent inhibition of IgE isotype switching by TLR9 ligation in human B cells. Clin. Immunol. 183, 263-265, https://doi.org/10.1016/j.clim.2017.08.020 (2017).

76. McDonald, D. M., Yao, L. C. \& Baluk, P. Dynamics of airway blood vessels and lymphatics: lessons from development and inflammation. Proc. Amer. Thor. Soc. 8, 504-507, https://doi.org/10.1513/pats.201102-022MW (2011).

77. Warburton, D. et al. Lung organogenesis. Curr. Top. Dev. Biol. 90, 73-158, https://doi.org/10.1016/s0070-2153(10)90003-3 (2010).

78. Semple, B. D., Blomgren, K., Gimlin, K., Ferriero, D. M. \& Noble-Haeusslein, L. J. Brain development in rodents and humans: Identifying benchmarks of maturation and vulnerability to injury across species. Prog. Neurobiol. 106-107, 1-16, https://doi. org/10.1016/j.pneurobio.2013.04.001 (2013).

79. Depino, A. M. Perinatal inflammation and adult psychopathology: From preclinical models to humans. Semin. Cell Devel. Biol., https://doi.org/10.1016/j.semcdb.2017.09.010 (2017).

80. O'Driscoll, D. N., Greene, C. M. \& Molloy, E. J. Immune function? A missing link in the gender disparity in preterm neonatal outcomes. Expert Rev. Clin. Immunol. 13, 1061-1071, https://doi.org/10.1080/1744666x.2017.1386555 (2017).

81. Ghosh, S. \& Klein, R. S. Sex Drives Dimorphic Immune Responses to Viral Infections. J. Immunol. 198, 1782-1790, https://doi. org/10.4049/jimmunol.1601166 (2017).

\section{Acknowledgements}

We thank Dr. Crystal Thomas and members of the animal facility for helpful discussions and careful maintenance of mouse lines. This work was supported by the Intramural Program of NIH, NIAID.

\section{Author Contributions}

K.L. designed and performed research, analyzed data, and wrote the paper. P.D. performed research. P.G.-F. analyzed data and wrote the paper.

\section{Additional Information}

Supplementary information accompanies this paper at https://doi.org/10.1038/s41598-018-30767-1.

Competing Interests: The authors declare no competing interests.

Publisher's note: Springer Nature remains neutral with regard to jurisdictional claims in published maps and institutional affiliations.

Open Access This article is licensed under a Creative Commons Attribution 4.0 International License, which permits use, sharing, adaptation, distribution and reproduction in any medium or format, as long as you give appropriate credit to the original author(s) and the source, provide a link to the Creative Commons license, and indicate if changes were made. The images or other third party material in this article are included in the article's Creative Commons license, unless indicated otherwise in a credit line to the material. If material is not included in the article's Creative Commons license and your intended use is not permitted by statutory regulation or exceeds the permitted use, you will need to obtain permission directly from the copyright holder. To view a copy of this license, visit http://creativecommons.org/licenses/by/4.0/.

(c) The Author(s) 2018 